\title{
EXPRESSÕES E SIGNIFICADOS DO CIRCUITO INFERIOR DA ECONOMIA
}

\section{URBANA DE IMPERATRIZ: uma análise através das dinâmicas materializadas na}

\author{
feira livre do Mercadinho
}

\author{
Bruno Lima \\ Licenciado em Geografia - UEMA \\ proflimabruno@gmail.com \\ Jailson de Macedo Sousa \\ Professor de Geografia - UEMASUL \\ geoparsagada@gmail.com
}

\section{Resumo}

Diante do reconhecimento da importância assumida pelo segmento terciário de Imperatriz e as características e significados do circuito inferior da economia urbana de deste município, buscamos neste estudo, entender as suas expressões para economia imperatrizense. Dentre os motivos ressaltados para a realização da presente pesquisa, está a necessidade de reconhecer as causas e os fatores que determinaram o surgimento do setor informal da economia. E ainda saber quais são as contribuições deste segmento para a economia da cidade de Imperatriz, e consequentemente, entender quais são os possíveis problemas gerados por ele à cidade. Buscamos entender a dinâmica do circuito inferior e do superior da economia urbana, pois entende-se que para o circuito inferior existir é necessário que haja um circuito superior. Este primeiro, em muitos momentos, vai precisar de algumas manutenções que são encontradas no segundo circuito. A presente pesquisa objetiva ainda, conhecer o público alvo consumidor do circuito inferior da economia urbana, quem são e porque preferem consumir os produtos ofertados por este segmento.

Palavras-chave: Geografia Urbana. Circuito inferior. Imperatriz.

\begin{abstract}
Before the recognition of the importance assumed by the tertiary segment Empress and the characteristics and meanings of the lower circuit of the urban economy of this municipality, we seek in this study, understand their expressions to Imperatrizense economy. Among the salient reasons for the realization of this research is the need to recognize the causes and factors that led to the emergence of the informal sector of the economy. And yet know what are the contributions of this sector to the economy of the city of Imperatriz, and consequently understand what are the possible problems generated by it to the city. We try to understand the dynamics of the lower and upper circuit of the urban economy, it means that for the lower circuit exist there must be a higher circuit. This first, in many instances, will need some maintenance that are found on the second circuit. This research aims to further meet the consumer target audience of the lower circuit of the urban economy, who are and why they prefer to consume the products offered by this segment.
\end{abstract}

Keywords: Urban Geography. lower circuit. Imperatriz.

Recebido em 03/08/2016 / Aprovado para publicação em 26/04/2019.

OBSERVATORIUM: Revista Eletrônica de Geografia, v. 9, n. 3, p. 313-336. set./dez. 2018. 


\title{
Introdução
}

A cidade de Imperatriz tem afirmado desde a década de 1980 as suas bases e estruturas econômicas no segmento terciário, de acordo com Sousa (2015)

\begin{abstract}
Na cidade de Imperatriz, a consolidação deste segmento ocorreu a partir da década de 1980, sendo que as décadas posteriores têm registrado uma crescente expansão destes setores. A área que abriga parcelas mais expressivas destas modalidades de comércio é o bairro Mercadinho. No entanto, é possível notar nas últimas décadas uma desconcentração destas atividades econômicas para outras áreas da cidade. Trata-se dos bairros: Bacuri e Nova Imperatriz que passaram a acolher expressivas fatias de equipamentos ligados ao comércio. (SOUSA, 2015, p. 403)
\end{abstract}

A atividade comercial e a prestação de serviços se apresentam de fato como as atividades econômicas mais dinâmicas e importantes desta cidade. Este fato pôde ser constatado em razão do produto interno bruto de Imperatriz que tem sido conduzido, prioritariamente, pela forte participação do setor terciário. Segundo os dados do IBGE no ano de 2013, o valor adicional bruto dos serviços a preços correntes teve media de $\mathrm{R} \$ 2.828 .112$ ao mês no conjunto total do PIB de Imperatriz.

Esta atual conjuntura econômica se dá, principalmente, pelo fato de haver desde a década de 1980 uma forte relação da cidade com o comércio. Este que fez com que Imperatriz se destacasse no cenário regional, como importante polo de atração pelos setores atacadista e varejista, devido sua intensa atividade comercial e também de prestação de serviços diversos, como por exemplo, de saúde e educação.

\section{A natureza e os significados dos dois circuitos espaciais da economia urbana}

Os dois circuitos da economia urbana são elementos que existem, principalmente, nos países periféricos. O primeiro circuito, o superior, é o que mais se destaca em termos de organização e investimentos do capital. O segundo circuito, o inferior, passou a existir desde o momento em que uma parcela da população não conseguiu ser absorvida pelo primeiro circuito, tanto como mão de obra, quanto como consumidora. Os dois circuitos da economia se distinguem em diversas formas. A respeito disto Cataita e Silva (2013) ponderam

Os circuitos da economia urbana distinguem-se principalmente pelas diferenças no uso dos capitais, da tecnologia e da organização das atividades e hoje importa considerar (i) o aprofundamento da interdependência dos lugares, (ii) as diferenças e desigualdades regionais, (iii) o uso de novas tecnologias pelo circuito inferior, (iv) a 
expansão do crédito e do consumo entre os pobres e, por fim, (v) a avaliação dos ramos de atividades, ou seja, a avaliação dos circuitos espaciais de produção por ramo de atividade. (CATAIA; SILVA, 2013, p. 64)

Desse modo, observa-se que os dois circuitos da economia urbana se diferenciam, principalmente, no uso dos capitais em relação à tecnologia empregada em ambos circuitos, onde um se organiza mais que o outro, sendo que o mais organizado é o circuito superior.

O circuito superior da economia surge das atividades comerciais oriundas dos lucros do grande capital advindo, em particular, das atividades industriais. Tornou-se necessário comercializar os produtos provenientes das manufaturas e, posteriormente, das indústrias. Organizá-lo não é tarefa simples, pois esse circuito começou pequeno, de maneira a suprir, antes de tudo, as necessidades da população.

Desse modo, o circuito superior da economia passou a ocupar as principais áreas urbanas. Pois para este se desenvolver e também atrair um maior número de clientes, seria necessário uma ótima localização, com as melhores ruas da cidade, onde o trânsito de veículos e pessoas fosse facilitado. Sposito (1996) define o circuito superior

[...] seria definido por capital abundante; tecnologia mais avançada na produção; exportação dos produtos acabados; organização bem burocratizada; assalariamento de toda força de trabalho; e grande estocagem de produtos. A essas características, pode-se acrescentar a proporção da área ocupada pelos estabelecimentos em relação à áreas do equipamento econômico urbano e sua localização periférica, buscando ou se utilizando de instalações ora existentes ou mesmo de áreas antes não pertencentes ao perímetro urbano. (SPOSITO, 1996, p. 45)

O circuito superior da economia encontra-se bem organizado, sendo burocratizado. Utiliza, via de regra, tecnologia avançada, principalmente da computação. Busca em sua força de trabalho, profissionais qualificados para exercerem bem suas funções. Este circuito da economia urbana ainda ocupa grandes áreas, sendo que todos que compõe este segmento da economia buscam as proximidades de seus concorrentes, visando dar mais opções aos seus clientes.

O Estado pode ser considerado um grande parceiro do circuito superior da economia, pois com suas políticas de facilitação para instalação de grandes empresas, sobretudo, multinacionais, adota a isenção de alguns impostos e tarifas para poder atrair grandes empresas que atuam em diversos ramos. Outro fator que deve ser considerado é a política de financiamentos e de melhoramento de infraestrutura que o Estado adota em favorecimento do circuito superior. Sobre este fato Sposito (1996) afirma 
Outro importante elemento ligado ao circuito superior é o Estado, através de suas políticas de desenvolvimento, financiando e favorecendo grandes firmas pelas políticas de impostos e como fornecedor de infraestruturas, que se empobrece paulatinamente, tornando-se cada vez "menos Estado" (SPOSITO, 1996, p. 45)

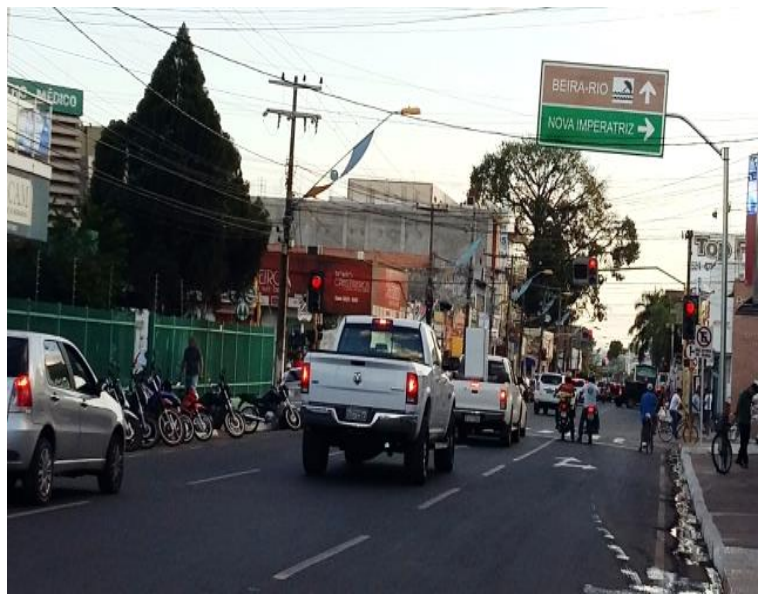

Foto 1: Imperatriz/MA - Setor varejista. Av. Dorgival/Centro comercial Fonte: http://www.imperatriz.ma.gov.br Acesso em: 20/12/2015

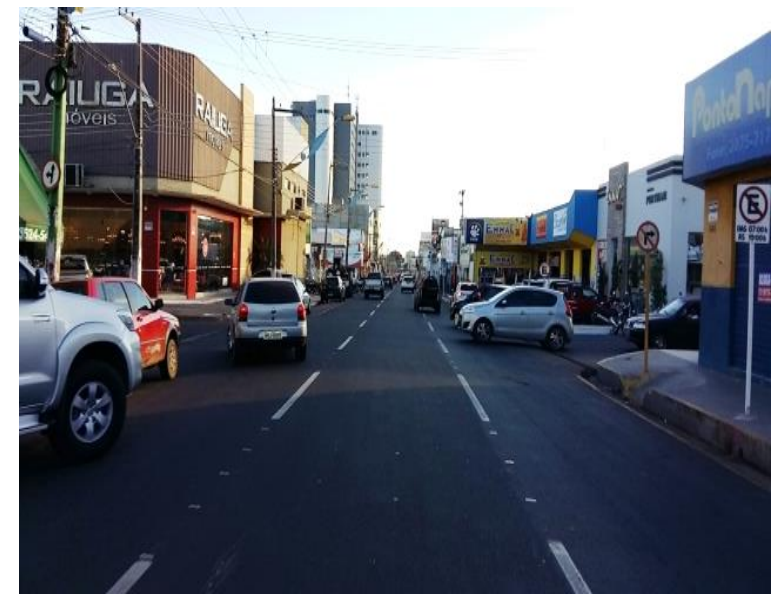

Foto 2: Imperatriz/MA - Setor varejista. Av. Dorgival/Centro comercial Fonte: http://www.imperatriz.ma.gov.br Acesso em: 20/12/2015

O circuito inferior se caracteriza pela facilidade de se encontrar trabalho. Mas essa facilidade em achar trabalho dentro deste circuito, não é garantia de um bom salário, pois são frentes de emprego onde a maioria dos empregadores não conseguem oferecer um salário mínimo. Disto surge o circuito inferior da economia, onde uma grande contingente populacional consegue ocupação, mesmo que não seja com uma boa remuneração. Sobre o circuito inferior Pintaudi (1999) comenta

Trata-se de uma atividade extremamente hierarquizada e que, numa sociedade em que grande número de pessoas não encontra emprego, se torna um meio de garantir a sobrevivência, esta também muito diferenciada entre eles. (PINTAUDI, 1999, p. 150)

A sobrevivência é outro fator relevante dentro do circuito inferior, pois ao contrário do circuito superior, no circuito inferior o mais importante não a acumulação do capital, mas a sobrevivência dos negócios e de quem depende dele. Neste segmento da economia muita coisa pode ser reaproveitada ou usada de diversas formas em várias ocasiões. A respeito disso Santos (2004) comenta:

O circuito inferior também poderia ser bem definido segundo a fórmula de Lavoisier: "Nada se perde, nada se cria, tudo se transforma..." O jornal usado tornase embalagem, o pedaço de madeira se transforma em cadeira, as latas, em reservatórios de água ou em vasos de flores etc [...] (SANTOS, 2004, p. 199) 
Desse modo, pode-se afirmar que o circuito inferior da economia também é o circuito do improviso, do "jeitinho", pois com os mais diferentes materiais pode-se fazer novas coisas. É o circuito da economia, onde na maioria das vezes, o mais importante não é a forma ou a aparência, mas sim o bom trato com o freguês, o "corpo a corpo", onde não existem linhas de crédito complexas, baseadas em cartões ou similares, mas sim da confiança.

O circuito inferior da economia sofre uma grande dependência dos agentes intermediários da economia. Trata-se dos setores atacadistas e de transporte, pois a maioria dos pequenos comerciantes não dispõe de condições de ir até os centros distribuidores para coleta de produtos para a revenda.

É nesse sentido que o circuito inferior depende do circuito superior da economia. A desigualdade de renda é o principal fator para que haja esta interdependência. São impossibilidades estruturais que fazem com que o circuito inferior seja refém do setor atacadista. Sobre essa relação de dependência Santos (2004) comenta

[...] Quanto mais pobre é o indivíduo, mais ele depende dos intermediários para se abastecer. Essa dependência aumenta com o tamanho da cidade: nas pequenas cidades, por exemplo, é possível evitar um certo número de intermediários na alimentação. (SANTOS, 2004, p. 225)

O que podemos concluir é que de diversos modos o circuito inferior depende do circuito superior, primeiramente pela sua existência, onde ele não seria possível ou necessário, se o circuito superior atendesse todas as camadas sociais e absorvesse toda a mão de obra disponível nas cidades. $\mathrm{O}$ circuito inferior depende da produção e distribuição dos produtos provenientes do circuito superior, pois muitos comerciantes do segundo segmento não portam de condições sequer de ir à busca das mercadorias para comercialização, dependendo assim do setor atacadista e das transportadoras.

Com vistas de apreender o dinamismo que é peculiar do circuito inferior da economia urbana é que apresentamos aspectos essenciais da sua configuração no bairro Mercadinho, na cidade de Imperatriz-MA.

O circuito inferior da economia e suas expressões na cidade de Imperatriz: uma interpretação através das dinâmicas socioeconômicas no Bairro Mercadinho 
IMPERATRIZ: uma análise através das dinâmicas materializadas na feira livre do Mercadinho

Bruno Lima; Jailson de Macedo Sousa

A cidade de Imperatriz tem sua estrutura econômica bem definida, pautada principalmente no setor de comércio e serviços. Mas há também atividades agrícolas e industriais. Esta estrutura tem heranças dos ciclos econômicos ${ }^{1}$, que geraram lucros e possibilitaram investimentos em outros setores. O crescimento urbano da cidade tem características irregulares, pois seu crescimento foi de maneira desordenada, o que se pode perceber nas ruas irregulares e nas quadras sem padrões definidos.

As atividades econômicas têm definido desde o princípio, contribuindo para o crescimento da cidade de Imperatriz. A cada ciclo econômico, mais e mais pessoas vinham das mais distantes regiões do país, ocupavam a cidade e fizeram com que novos bairros surgissem. As atividades terciárias são consideradas as principais molas propulsoras para o crescimento de Imperatriz. Novos bairros surgiram para satisfazer as necessidades de moradia da população e com esta expansão territorial se expandiu o comércio, para atender as necessidades da população. A respeito desse processo Sousa (2005) afirma

\begin{abstract}
O processo de expansão da malha urbana na cidade de Imperatriz apresenta estreitos vínculos com a difusão das atividades terciárias nesta cidade. A criação de novos espaços, ou seja, de novos bairros sofreu e tem sofrido as intervenções diretas do mercado que tem se preocupado com a especialização destas áreas. Muitos bairros foram surgindo em Imperatriz após a década de 1970 e com estes, surgiram também, as demandas pelas atividades comerciais e pelos serviços de educação, saúde, lazer e etc. A expansão da malha urbana, desse modo, está diretamente relacionada à difusão destas atividades econômicas no interior da cidade. (SOUSA, 2005, p. 116)
\end{abstract}

Desse modo, pode-se afirmar que o processo de crescimento urbano de Imperatriz apresenta-se como consequências das atividades econômicas inserida neste espaço. Tendo como principal motivo do aumento da malha urbana o setor terciário da economia.

Outro fator relevante para o crescimento territorial e econômico de Imperatriz foi a difusão dos setores atacadista e varejista. Estes setores se fixaram na cidade antes da década de 1980 e se firmaram de maneira vigorosa, pois como já dito, Imperatriz passou a ser um grande entreposto comercial, não somente para cidades do Maranhão, mas também para algumas regiões dos estados do Pará e Tocantins. A respeito dos papéis destes setores do comércio Sousa (2015) comenta

\footnotetext{
Afirmou-se antes que a década de 1980 é entendida como um marco central na difusão das atividades terciárias na cidade de Imperatriz. Desde então tem se observado uma crescente participação dos segmentos vinculados ao comércio atacadista e varejista nesta cidade, sendo que a relevância destes setores também se projeta para a região Sulmaranhense. (SOUSA, 2015, p. 348)
} 
Com relação ao comércio varejista da cidade de Imperatriz, cabe ressaltar a importância do circuito inferior da economia urbana, dependente do setor atacadista, que é de onde advém a maioria dos produtos comercializados neste segmento. Vale destacar a importante participação deste setor da economia no interior desta cidade. Trindade Júnior (2013) ao estudar as relações entre o comércio e a cidade destaca:

Para se trabalhar com o comércio e os serviços em determinadas cidades não basta apenas centrar a análise nas atividades ditas formais, tais como as redes de supermercados, as concessionárias de automóveis, a rede bancária e financeira, as lojas de departamentos, os serviços de saúde e de educação. É preciso entender também o papel das feiras, ou seja, dos mercados e dos transportes alternativos como formas de articulações contínuas e contraditórias àqueles circuitos formalmente reconhecidos. (TRINDADE JÚNIOR, 2013, p. 83)

O circuito inferior se materializa em vários espaços da cidade de Imperatriz. No entanto, este circuito é mais nítido principalmente do Bairro Mercadinho que é o espaço que foi escolhido para a realização desta pesquisa. Estes espaços de comércio se configuram de diversas maneiras, onde pode-se observar vendedores ambulantes, outros fixados nas calçadas e alguns que ocupam pontos comerciais fixos alugados ou cedidos pela prefeitura da cidade, sendo preciso pagar apenas algumas taxas para permanência no local. Segundo dados da secretaria de abastecimento do município são 228 feirantes que trabalham na feira livre do bairro. A respeito da influência conferida à feira livre do Mercadinho, Sousa (2015) comenta

No conjunto das feiras livres presentes na cidade de Imperatriz é notória a influência conferida à feira do Mercadinho. Esta importância é explicada tanto pela variedade como pela quantidade de produtos que nela são comercializados e ainda em face da quantidade de estabelecimentos e de feirantes que nela são encontrados. Esta é a principal área de comercialização de produtos varejistas voltados ao setor alimentício de Imperatriz. (SOUSA, 2015, p. 350)

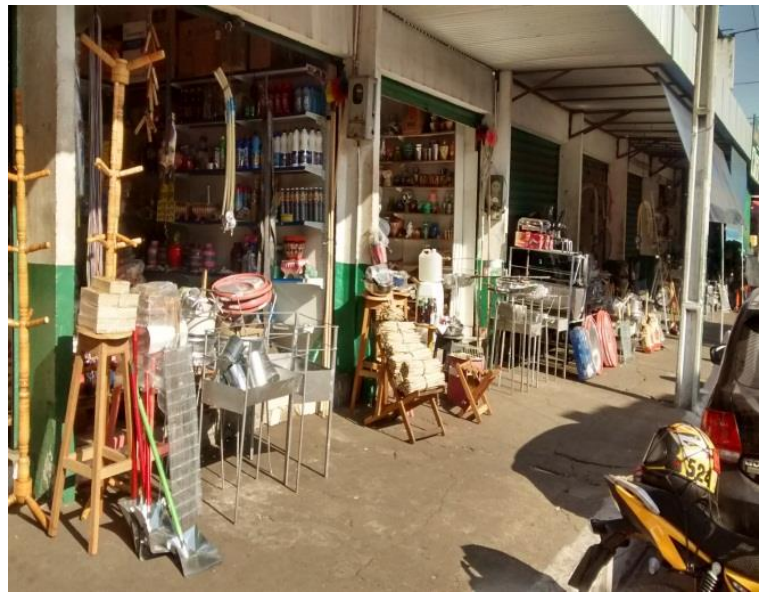

Foto 3: Imperatriz/MA - Feira do Mercadinho.

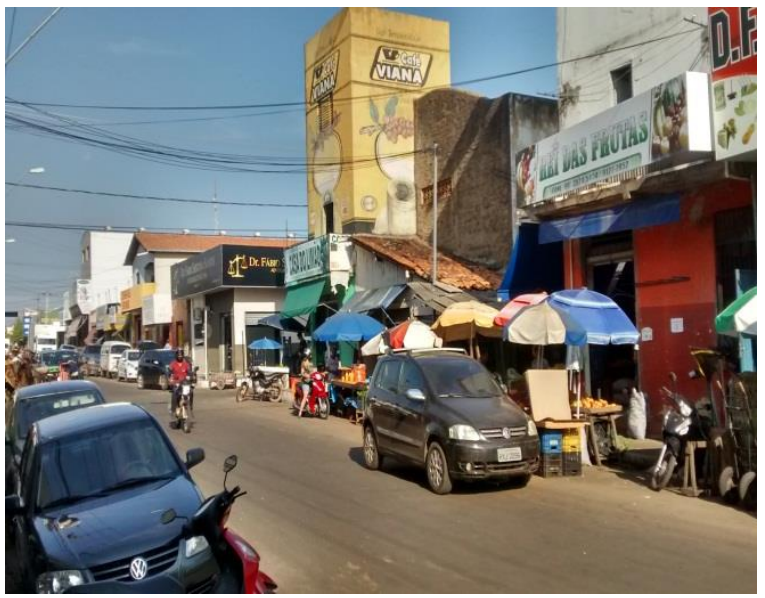

Foto 4: Imperatriz/MA - Feira do Mercadinho.

OBSERVATORIUM: Revista Eletrônica de Geografia, v. 9, n. 3, p. 313-336. set./dez. 2018. 
Setor de utensílios domésticos

Fonte: Lima (2015)
Setor Alimentício

Fonte: Lima (2015)

Desse modo reafirmamos a importância das formas de comércio no bairro Mercadinho, onde os produtos alimentícios têm grande importância, embora estes também sejam encontrados diversos produtos, tais como, eletrônicos, serviços de concertos em geral, e calçados. O próximo tópico está relacionado aos resultados da pesquisa realizada no bairro Mercadinho. Mostrando a realidade dos clientes e comerciantes e a importância deste espaço comercial para o crescimento econômico da cidade de Imperatriz, com ênfase num estudo particularizado acerca dos significados do circuito inferior da economia urbana materializado no bairro Mercadinho.

\section{Perfil socioeconômico dos comerciantes e clientes do circuito inferior da economia urbana no Bairro Mercadinho}

O circuito inferior da economia representa importantes elementos da estrutura comercial que se faz presente no mundo contemporâneo. Estas plataformas comerciais tem se inserido cada vez mais no contexto dos espaços urbanos e passaram a fazer parte da realidade das cidades contemporâneas.

Segundo Milton Santos (2004, p. 220), "é preciso entender a estrutura demográfica para explicar a estrutura econômica das cidades". Para tal são consideradas as seguintes variáveis: crescimento demográfico, influenciado pelas migrações internas e externas e a composição da população urbana, considerando-se nacionalidades e etnias, sexo, estrutura etária, natalidade e mortalidade. Já as estruturas sociais - diferenças de renda na cidade, diferenças de consumo, os dois circuitos de produção e o papel da população urbana sobre o setor produtivo - estão relacionadas a aspectos da economia urbana que correspondem à existência de assalariados e não assalariados, a nacionalidade e a profissão, bem como a nacionalidade e a renda.

Estes segmentos comerciais evoluíram bastante nos últimos anos no Brasil. Suas singularidades somadas ao fator moderno de comércio são um atrativo para milhares de pessoas, comerciantes e clientes.

É diante desta lógica que envolve a implantação do comércio no bairro Mercadinho que o setor informal adquire intensa importância, influência e participação no segmento 
comercial de Imperatriz. Como prova desta influência econômica que tem sido orientada por estas formas de comércio é que expomos a seguir alguns dados relativos à quantidade de feiras livres presentes na cidade de Imperatriz no ano de 2014.

\section{Quadro 1: Imperatriz/MA - Principais feiras/mercados livres do município}

\begin{tabular}{|c|c|c|c|}
\hline Denominação & Localização/Bairro & Quantidades de Feirantes & Organizações \\
\hline Feira do Bom Sucesso & Bom Sucesso/Santa Rita & 78 & Não \\
\hline Feira do Bacuri & Bairro Bacuri & 146 & Sim \\
\hline Feira do Mercadinho & Bairro Mercadinho & 228 & Sim \\
\hline Feira da Nova Imperatriz & Bairro Nova Imperatriz & 102 & Sim \\
\hline Feira da Vila Lobão & Bairro Vila Lobão & 88 & Não \\
\hline Feira/Mercado Bom Jesus & Bairro Centro & 38 & Não \\
\hline Total & $\mathbf{0 6}$ & $\mathbf{6 8 0}$ & - \\
\hline
\end{tabular}

Fonte: Secretaria de Abastecimento do Município de Imperatriz, 2014.

Organização: Jailson de Macedo Sousa, 2015.

Os dados antes expostos nos remetem a pensar na importância assumida pelas feiras/mercados livres no contexto da economia imperatrizense. Conforme a Secretaria de Abastecimento do Município de Imperatriz no ano de 2014 existiam pelo menos 680 feirantes no município. Ao considerar este dinamismo podemos observar que a feira livre do bairro Mercadinho apresenta destaque na quantidade de feirantes inseridos neste espaço de comercialização. Isto demonstra que esta feira é a maior e a mais importante da cidade.

Vale destacar também a importância destas plataformas comerciais em relação à geração de empregos diretos e indiretos. Foi possível constatar em razão dos dados expostos no quadro 6 que no ano de 2014 as feiras livres empregavam centenas de pessoas. Esses números da geração de empregos nas feiras livres de Imperatriz se expandiram significativamente. 


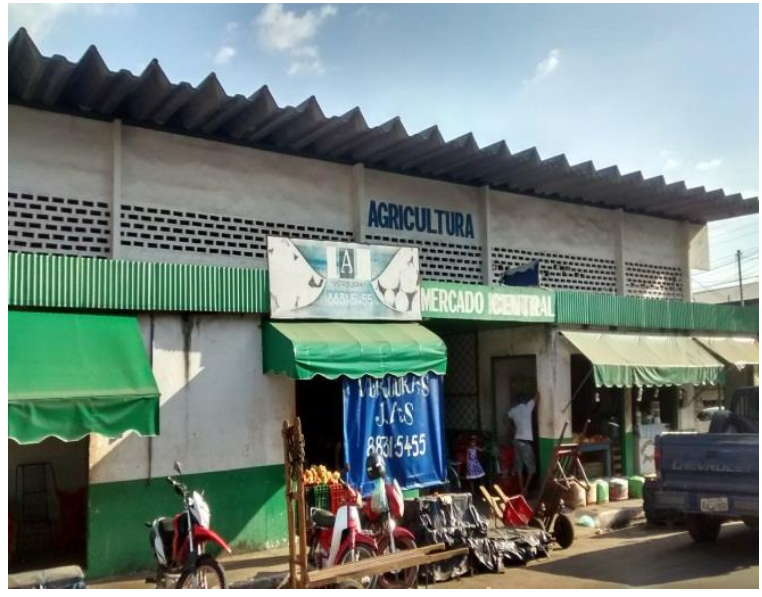

Foto 5: Imperatriz/MA - Feira do Mercadinho. Mercado central Fonte: Lima (2015)

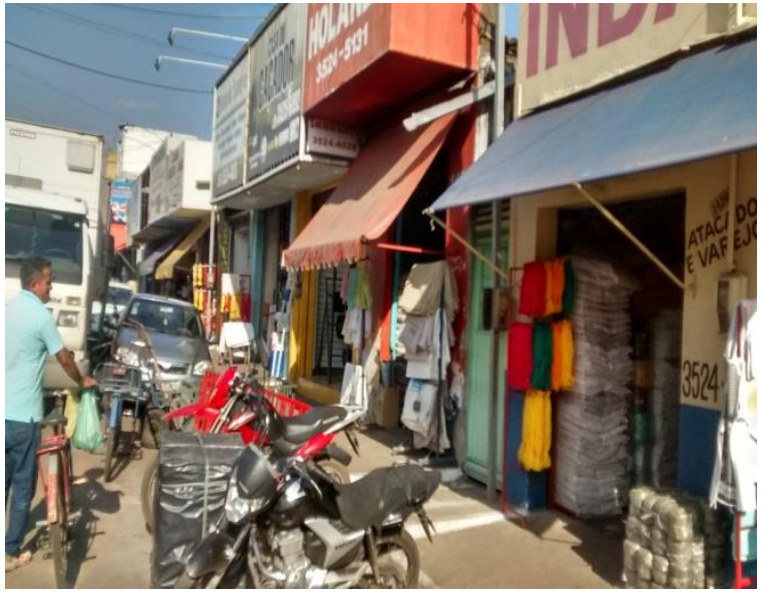

Foto 6: Imperatriz/MA - Feira do Mercadinho. Setor de produtos diversos Fonte: Lima (2015)

Dessa forma é importante reafirmar os objetivos centrais que foram delineados a este estudo que se buscou identificar a importância econômica do circuito inferior da economia urbana, para assim entendermos a dinâmica econômica de Imperatriz e a sua importância regional. Associada a esta finalidade mais ampla é necessário ressaltar as finalidades específicas propostas a esta investigação;

* Compreender a estrutura e as funções socioeconômicas das atividades comerciais que integram o circuito inferior da economia urbana desenvolvido no bairro Mercadinho em Imperatriz-MA.

* Analisar a estrutura socioeconômica do circuito inferior da economia urbana no bairro mercadinho;

* Identificar as contribuições socioeconômicas do circuito inferior para a economia do município de Imperatriz.

* Investigar qual é o público alvo consumidor e os distribuidores desses espaços de comercialização, que abastece esses espaços do circuito inferior.

Relacionadas às finalidades antes expostas é válido mencionar também os instrumentais metodológicos que serviram de base a este estudo, ou seja, é necessário enfatizar as contribuições metodológicas que serviram de fundamentos para a realização da presente pesquisa que por ora apresentamos.

A pesquisa realizada se direcionou aos comerciantes e clientes da feira livre do bairro Mercadinho na cidade de Imperatriz. A presente pesquisa foi realizada entre os meses de novembro e dezembro de 2015. Antes de expor os resultados obtidos por meio desta coleta de 
dados é necessário reafirmar os instrumentos metodológicos que nortearam a realização deste estudo.

Para a coleta de dados, optamos por trabalhar com a técnica de entrevistas, sendo que estas obedeceram ao caráter padronizado. (LAKATOS, 2006). Interessa enfatizar que do ponto de vista metodológico associado à adoção das entrevistas padronizada elegemos trabalhar com a observação denominada de simples. (LAKATOS e MARCONI, 2003).

É válido ressaltar que a realização de entrevistas levou em conta a utilização do modelo padronizado, ou seja, com a elaboração de perguntas abertas e fechadas para melhor aproveitamento dos relatos obtidos através das falas dos entrevistados. Foram direcionadas as entrevistas tanto aos clientes como aos comerciantes do bairro Mercadinho. No total, foram realizadas 20 (vinte) entrevistas, sendo que estas foram divididas de forma que foram feitas 10 (dez) para clientes e $10(\mathrm{dez})$ para comerciantes.

$\mathrm{Na}$ parte que coube a entrevista dirigida aos clientes, foram indicadas 06 (seis) perguntas com o intuito de obter informações que respondessem aos objetivos propostos a este estudo. Abaixo apresentamos estes questionamentos.

* Qual cidade você reside atualmente?

* Quantas vezes por mês você costuma se deslocar ao bairro Mercadinho?

* Qual a finalidade das compras realizadas no bairro Mercadinho?

* Porque você opta por fazer compras no bairro Mercadinho de Imperatriz?

* Na sua opinião, o setor informal é importante para o crescimento da cidade? Por quê?

* O poder público municipal/estadual tem feito alguma ação no sentido de estruturar este segmento econômico? Como?

Cabe destacar que foi realizado um total de 10 (dez) entrevistas aos clientes do bairro mercadinho. Estas foram aplicadas de forma aleatória, ou seja, não priorizamos um estabelecimento específico. Na segunda etapa de realização do trabalho empírico, ou seja, do levantamento do trabalho de campo, foram realizadas 10 (dez) entrevistas, sendo que estas foram direcionadas aos comerciantes da feira livre do bairro mercadinho. Importa reafirmar que as entrevistas seguiram os mesmos padrões metodológicos estabelecidos aos clientes.

Preocupamo-nos em trabalhar com a adoção das técnicas de pesquisa da observação simples com base nas ideias metodológicas fundamentadas nas orientações fornecidas por Antonio Carlos Gil (2008). Outra opção metodológica foi trabalhar com a utilização de entrevistas padronizadas. Estes instrumentos metodológicos foram essenciais ao 
desenvolvimento desta pesquisa. Vale lembrar os questionamentos propostos nesta fase de realização da pesquisa, destacamos a seguir.

* Há quanto tempo este estabelecimento comercial está implantado no bairro Mercadinho?

* Que motivos foram levados em consideração para a instalação deste empreendimento no bairro mercadinho?

* Quais são os principais produtos comercializados neste estabelecimento comercial?

* De onde advêm os produtos comercializados neste estabelecimento comercial?

* De qual localidade (cidade) advêm a sua clientela?

* Por que você optou em instalar este empreendimento no bairro Mercadinho?

* Na sua opinião, o circuito inferior da economia é importante para o crescimento da cidade de Imperatriz? Por quê?

* O poder público municipal/estadual tem feito alguma ação no sentido de estruturar este segmento econômico? Como?

Através da realização da coleta de dados e das entrevistas que foram direcionadas aos comerciantes e clientes foi possível compreender a importância e os significados que esta plataforma comercial tem assumido no interior da cidade de Imperatriz e ainda no contexto da região Sulmaranhense, bem como para estados vizinhos.

Com relação à coleta dos dados empíricos, ou seja, a realização do trabalho de campo é importante ressaltar que foi realizado um total de 20 (vinte) entrevistas no bairro Mercadinho, sendo que estas foram distribuídas em dois blocos. Inicialmente apresentamos os dados obtidos através das 10 (dez) entrevistas que foram direcionadas aos clientes destes estabelecimentos comerciais, objetivando assim entender o fluxo dos mesmos e as suas opiniões relativas à importância local e regional destes estabelecimentos comerciais.

No segundo bloco apresentamos os dados colhidos através das 10 (dez) entrevistas que foram realizadas com os comerciantes do bairro Mercadinho, a fim de entender os fluxos de mercadorias e opiniões relativas a instalação e importância socioeconômica das plataformas comerciais representadas pelo circuito inferior da economia urbana.

Nesta primeira etapa da pesquisa empírica tivemos a inquietação de investigar:

* Localidade de residência dos clientes entrevistados;

* Frequência de visita à feira livre do bairro Mercadinho;

* Motivações de realizar compras na feira livre do bairro Mercadinho. 


\section{Gráfico 1: Localidade de residência dos clientes entrevistados e Frequência de visitas ao bairro Mercadinho/mês}

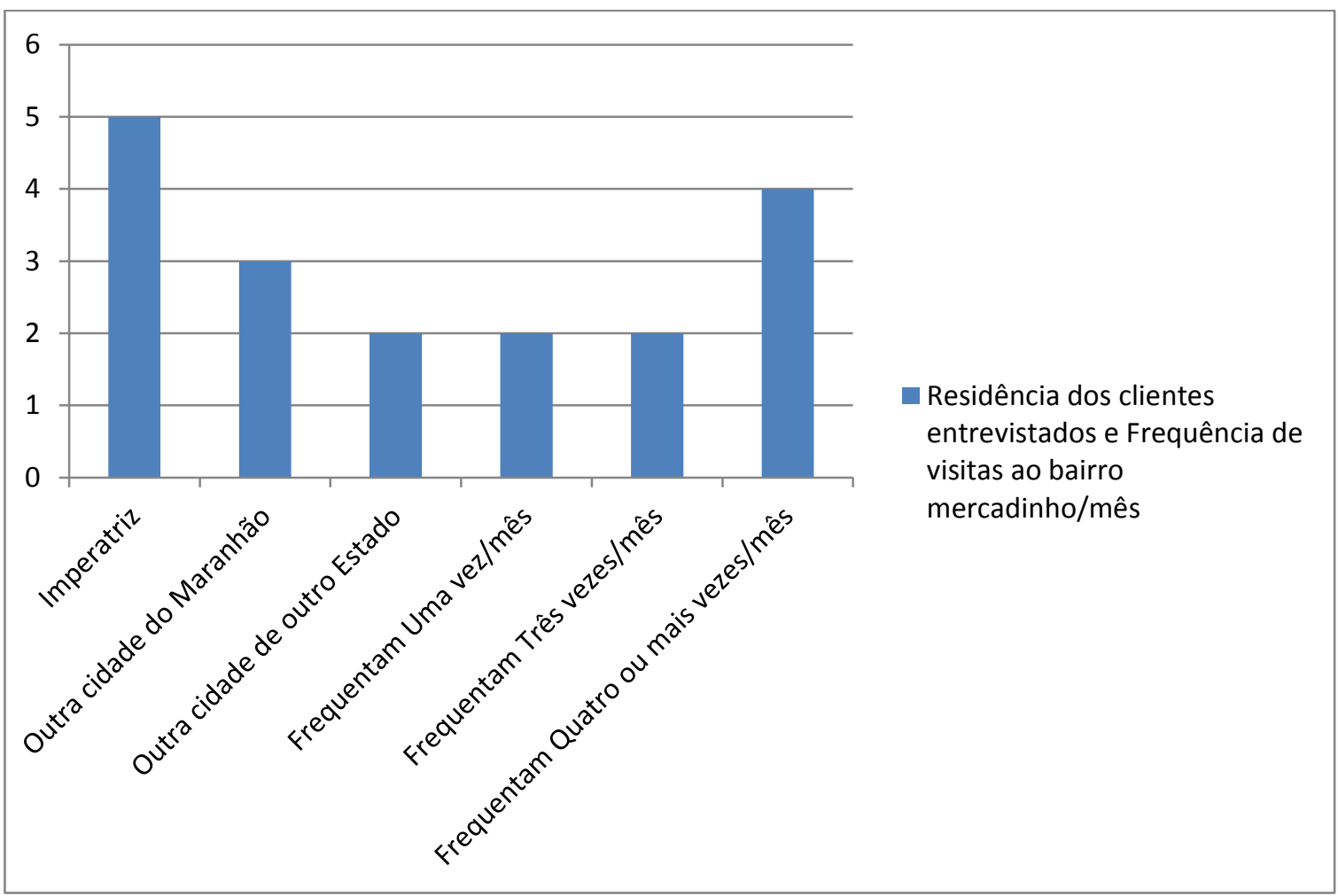

Fonte: Pesquisa direta - Bairro Mercadinho

Organização: Bruno Oliveira Lima, 2015.

Os dados expostos no gráfico 1 afirmam importantes contribuições para a compreensão da centralidade exercida pela feira livre do bairro Mercadinho. Dos clientes entrevistados, 05 (cinco) afirmaram que residem na própria cidade de Imperatriz, 3 (três) responderam que são oriundos de outras cidades do estado do Maranhão, que é o caso dos municípios de: Senador La Roque, Davinópolis e Açailândia. Os 02 (dois) restantes disseram advir de outras cidades de outros estados, como Sítio Novo do Tocantins no estado do Tocantins e Dom Eliseu no estado do Pará. Estes dados apresentados reforçam e confirmam os papéis e as funções regionais do comércio do bairro mercadinho em Imperatriz.

Sobre o papel de centralização representado pelo bairro Mercadinho, Sousa (2015) comenta:

O bairro Mercadinho também uma intensa mobilidade intra-urbana e interurbana que é gerada em função dos fluxos de pessoas, capitais, mercadorias e serviços que se dirigem dos diversos bairros de Imperatriz e das cidades circunvizinhas em busca dos produtos que são comercializados nesta área comercial da cidade de Imperatriz. (SOUSA, 2015, p. 405)

OBSERVATORIUM: Revista Eletrônica de Geografia, v. 9, n. 3, p. 313-336. set./dez. 2018. 
Essa afirmação confirma o papel de centralidade exercido por Imperatriz e pelo comércio informal do bairro Mercadinho. Outro questionamento direcionado aos clientes que recorrem ao bairro mercadinho se relaciona à necessidade de reconhecer e entender a frequência de visitas a estes estabelecimentos comerciais. Nossas atenções se voltaram a compreender os significados da mobilidade comercial.

Ainda ao analisar o gráfico 1, podemos notar que a frequência de visitas à feira livre do bairro Mercadinho é bastante significativa. Do total de 10 (dez) clientes entrevistados, 02 (dois) afirmam que vão ao bairro pelo menos uma vez por mês, 02 (duas) pessoas disseram que se deslocam ao menos três vezes ao mês à feira livre do bairro mercadinho e 06 (seis) pessoas afirmaram que vão ao bairro Mercadinho quatro ou mais vezes por mês.

Esses dados são importantes para entender a frequência com que os clientes visitam a feira livre do bairro mercadinho. Mesmo que seja variada esta frequência é possível entender que há um interesse explícito aos deslocamentos das populações da própria cidade de Imperatriz e ainda das cidades circunvizinhas e mesmo distantes, como dos estados do Pará e Tocantins em busca dos diversos produtos que são comercializados neste bairro.

Apresentamos ainda o questionamento sobre a finalidade das compras realizadas no bairro Mercadinho, buscando conhecer os motivos que tem levado os clientes a realizarem suas compras nestes estabelecimentos comerciais.

\section{Gráfico 2: Finalidades das compras realizadas no bairro Mercadinho}

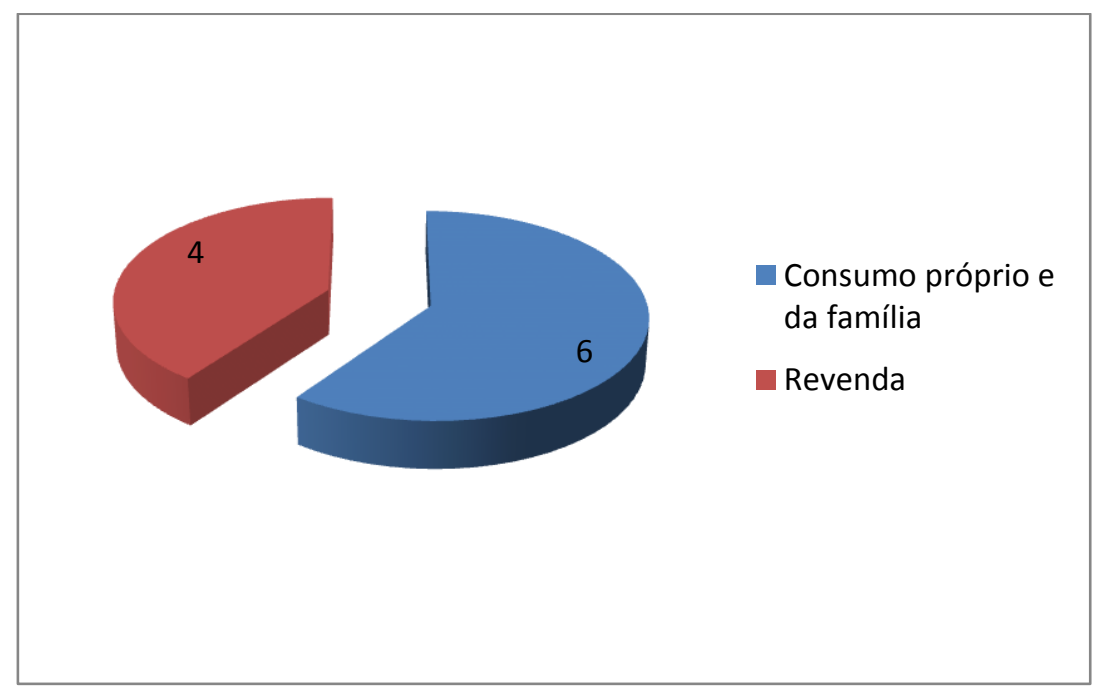

Fonte: Pesquisa direta - Bairro Mercadinho

Organização: Bruno Oliveira Lima, 2015. 
Os dados expostos no gráfico 2 retratam que dos 10 (dez) clientes entrevistados, 04 (quatro) admitiram que as compras efetuadas nestes estabelecimentos são voltadas para a revenda e 06 (seis) afirmaram que realizam as suas compras com a finalidade do consumo próprio e da família. Esses dados revelam que o foco principal do bairro Mercadinho é voltado ao varejo, ou seja, para atender as necessidades imediatas das localidades.

$\mathrm{O}$ quarto questionamento objetivou entender as principais motivações que têm levado os clientes a consumir os produtos que são comercializados no bairro Mercadinho em relação às compras efetuadas em seus estabelecimentos. Os resultados obtidos estão expostos no gráfico 5 indicado logo abaixo.

\section{Gráfico 3: Motivos de fazer compras no bairro Mercadinho}

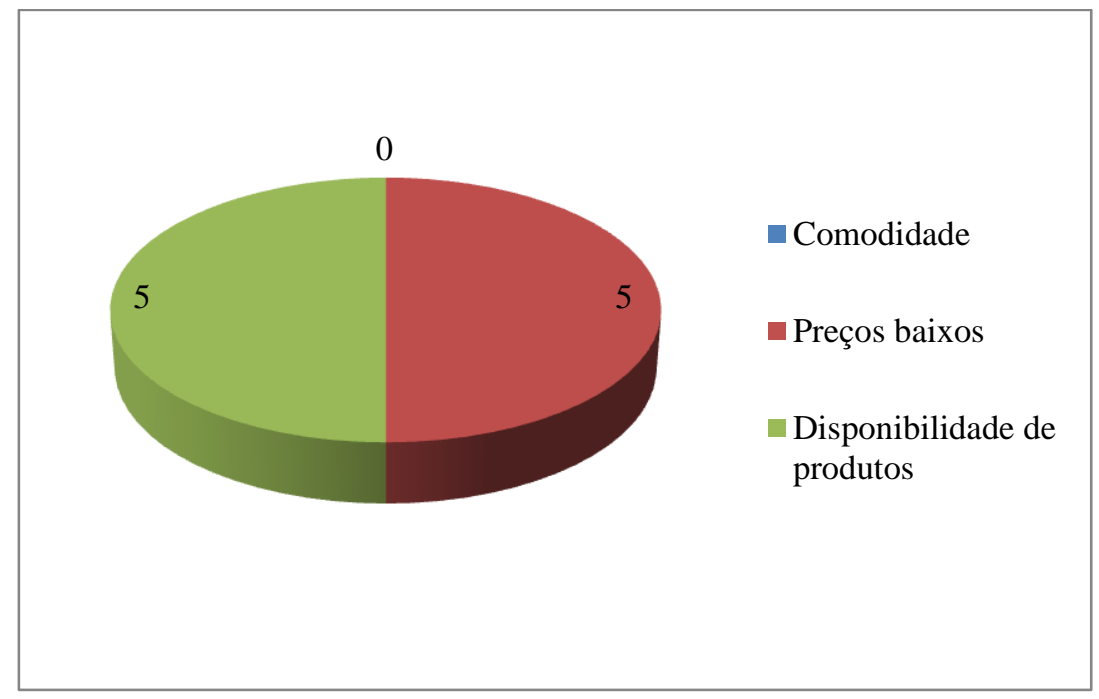

Fonte: Pesquisa direta - Bairro Mercadinho Organização: Bruno Oliveira Lima, 2015.

É importante destacar as singularidades que envolvem as motivações para a realização de compras no bairro Mercadinho. Nesse sentido, é notória a influência destes estabelecimentos comerciais, uma vez que abrigam além de uma variedade de produtos e serviços outros elementos que são atrativos aos clientes. Dito isto, foi possível observar que $50 \%$ dos clientes entrevistados destacaram os preços baixos dos produtos como o principal atrativo para as suas visitas ao bairro, o que corresponde a 5 (cinco) clientes entrevistados.

Ao considerar o mesmo questionamento, é possível inferir que $50 \%$ dos clientes entrevistados destacaram a disponibilidade de produtos como o principal atrativo, o que corresponde a 05 (cinco) pessoas. Nenhum cliente mencionou a comodidade como principal atrativo para realização de compras no bairro Mercadinho, o que nos leva a compreender que 
IMPERATRIZ: uma análise através das dinâmicas materializadas na feira livre do Mercadinho

Bruno Lima; Jailson de Macedo Sousa

mesmo tendo produtos com preços baixos e em grande variedade, a feira livre do bairro mercadinho não está oferecendo comodidade a seus clientes.

No quinto questionamento, buscamos compreender a visão e as opiniões dos clientes acerca da importância socioeconômica do setor informal da economia representado pela feira livre do bairro Mercadinho na cidade de Imperatriz. A seguir são expressas as falas dos entrevistados.

Sim! Porque são gerados empregos para muitas pessoas que estão fora do mercado de trabalho, mesmo que seja temporário. Se não existisse esse comércio no bairro mercadinho muitas pessoas passariam necessidades. (Cliente 1, entrevistada no bairro mercadinho dia 10/12/2015).

Sim! Porque muitas pessoas das cidades vizinhas acabam vindo aqui em decorrência da oferta de produtos e que geram empregos. Mesmo que não sejam moradores da cidade, mas se deslocam para comprar os produtos que são comercializados nestes estabelecimentos comerciais. (Cliente 2, entrevistada no bairro mercadinho dia 10/12/2015).

Sim! Porque existem muitos produtos e a ótimos preços, mesmo que não ofereça muita segurança e conforto para os clientes, mas também têm oportunidades de empregos para a população de Imperatriz e de outras cidades da nossa região. (Cliente 3 entrevistado no bairro mercadinho dia 10/12/2015).

Sim! Porque se por acaso esse tipo de comércio fosse proibido, muitas pessoas estariam sem trabalho e consequentemente sem renda para sustentar suas famílias. Além de dar opção para as pessoas que não podem consumir os produtos que são vendidos no setor formal, devido os preços não serem acessíveis. (Cliente 4 entrevistado no bairro mercadinho dia 10/12/2015).

Estas afirmações reforçam o que já foi dito até aqui sobre a importância do bairro Mercadinho para a cidade de Imperatriz. É fato evidente a centralidade que estes serviços e o comércio que oferecem para a cidade de Imperatriz e para a região Sulmaranhense. Esta centralidade pôde ser observada tanto em relação à atração de clientes de Imperatriz como também de toda a região. A singularidade assumida pelo bairro Mercadinho de Imperatriz se reflete em razão da grande clientela que atrai e também por concentrar uma variedade grande de produtos. Alguns clientes afirmaram também que preferem ir ao bairro mercadinho pela qualidade dos produtos que ali são comercializados.

Indagamos por fim aos clientes do bairro Mercadinho se eles consideram que o poder público municipal/estadual tem realizado alguma ação no sentido de estruturar este segmento econômico, ou seja, feito algum trabalho para dar mais conforto e comodidade para os comerciantes e clientes. Segue abaixo as falas dos entrevistados.

OBSERVATORIUM: Revista Eletrônica de Geografia, v. 9, n. 3, p. 313-336. set./dez. 2018. 
Não! Em todos esses anos que frequento o comércio neste bairro nunca vi nenhuma obra no sentido de melhorar estes espaços. (Cliente 5, entrevistada no bairro mercadinho dia 10/12/2015).

Não! A única ação que eu já percebi é uma mão de tinta que uma vez por ano a prefeitura passa na sarjeta das ruas e no mercado central, mas eu acho isso um trabalho insignificante em relação a tudo que deve ser melhorado. (Cliente 6, entrevistada no bairro mercadinho dia 10/12/2015).

Não! Nunca presenciei nenhuma ação para melhorar a feira livre do bairro mercadinho, nem organizar o trânsito das ruas a prefeitura consegue, é uma bagunça generalizada, muitos caminhões descarregando em pleno horário de pico, o que atrapalha muito quem vem de carro. (Cliente 7, entrevistado no bairro mercadinho dia 10/12/2015).

Sim! Eu vejo sempre os garis da prefeitura limpando e varrendo estes ambientes de comércio, apesar de toda a sujeira que os feirantes e comerciantes em geral deixam no chão, isso eu considero um ponto positivo. (Cliente 8 , entrevistado no bairro mercadinho dia 10/12/2015).

Mediante estas afirmações têm-se a confirmação de que na opinião da maioria dos clientes entrevistados, nem a prefeitura nem o governo do estado tem realizado algum trabalho no sentido de estruturar este segmento econômico. Os clientes consideram ainda que se dependesse da estrutura do bairro Mercadinho eles não consumiriam os produtos comercializados neste bairro. Apenas um cliente encontrou ponto positivo, na limpeza do ambiente.

Apresentamos a seguir o segundo bloco de entrevistas que foram dirigidas nesta fase da pesquisa empírica aos comerciantes do bairro Mercadinho. Vale ressaltar que procuramos obedecer aos mesmos critérios metodológicos que foram indicados aos demais atores investigados na pesquisa. Desse modo, a pesquisa primou por trabalhar com a observação simples e com a adoção de entrevistas padronizadas. Estes instrumentos fundamentaram-se nas ideias defendidas por Gil (2008). Buscamos através destas, analisar o fluxo de mercadorias, a localidade (cidade) de onde advêm estas e os motivos adotados pelos comerciantes na hora comercializar no bairro Mercadinho. A primeira indagação objetivou entender o tempo em que o estabelecimento comercial está implantado no bairro. Os resultados estão expostos a seguir. 


\section{Gráfico 4: Tempo de implantação do estabelecimento comercial no bairro Mercadinho}

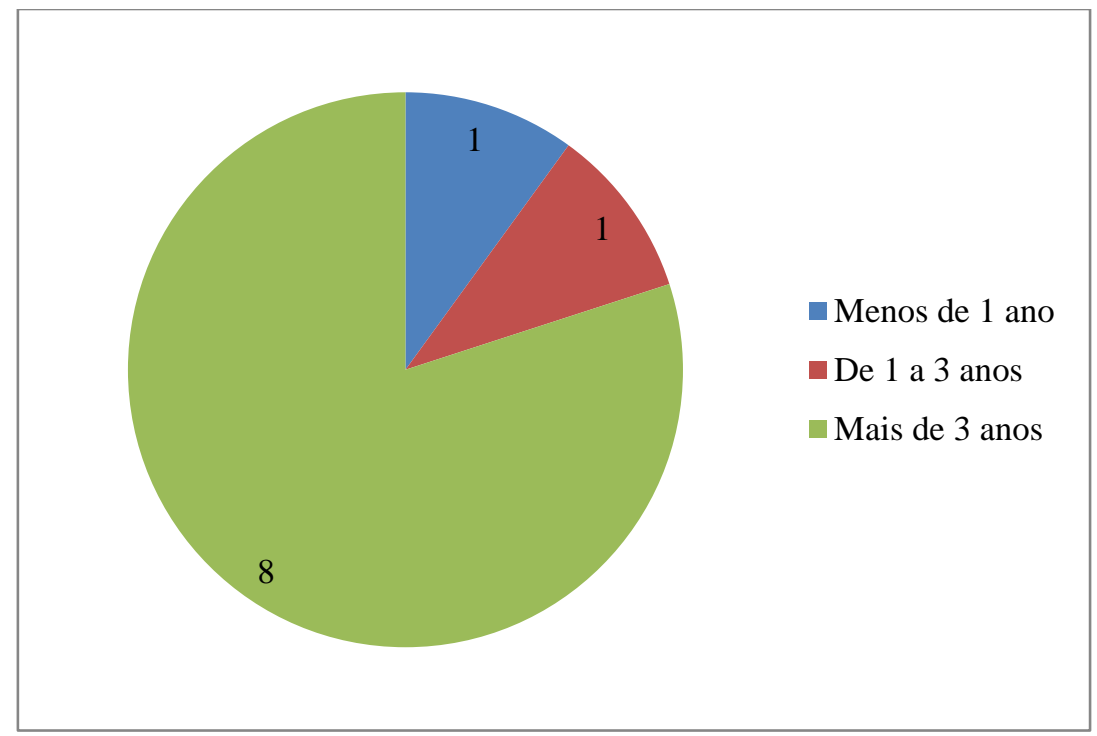

Fonte: Pesquisa direta - Bairro Mercadinho Organização: Bruno Oliveira Lima, 2015.

Os resultados expostos no gráfico 6 atestaram que a maioria dos estabelecimentos apresentou mais de três anos de instalação. Alguns comerciantes informam até que já estão trabalhando no bairro Mercadinho a mais de 30 anos. Desse modo, observados que $80 \%$ dos comerciantes entrevistados ( 08 comerciantes) admitiram que tivessem seus estabelecimentos comerciais instalados a mais de 03 (três) anos no bairro mercadinho. Logo $10 \%$ dos comerciantes, no total de 01 (um), afirma que seu estabelecimento está instalado no bairro a menos de 1 ano e $10 \%$ dos comerciantes, no total de 01 (um), afirma que seu estabelecimento está instalado no bairro de 1 a 3 anos.

Também tivemos a inquietação na realização desta pesquisa de questionar acerca dos principais produtos comercializados no bairro mercadinho. Diante das falas dos comerciantes pudemos observar que diversos produtos são comercializados neste bairro no conjunto dos demais setores comerciais presentes ali. O quadro abaixo reforça estas ideias.

\section{Quadro 1: Principais produtos comercializados no bairro mercadinho}

\begin{tabular}{|c|c|}
\hline Principais Produtos Comercializados & $\begin{array}{c}\text { Quantidade } \\
\text { de Lojas }\end{array}$ \\
\hline Calçados & 02 \\
\hline Grãos/Cereais & 03 \\
\hline Temperos & 03 \\
\hline Produtos eletrônicos & 01 \\
\hline
\end{tabular}




\begin{tabular}{|c|c|}
\hline Cosméticos/Medicamento Natural & 01 \\
\hline Total & $\mathbf{1 0}$ \\
\hline
\end{tabular}

Fonte: Pesquisa direta - Bairro Mercadinho

Organização: Bruno Oliveira Lima, 2015.

Dos 10 (dez) estabelecimentos comerciais investigados nesta pesquisa foi possível constatar que os principais produtos comercializados no bairro mercadinho são os grãos/cereais e os temperos, ou seja, $60 \%$ dos produtos comercializados. Consequentemente, este é o ramo que também é responsável pelo maior número de postos de trabalhos do bairro mercadinho, ou seja, de empregos gerados por este segmento.

Outro importante questionamento levantado buscou identificar e entender a origem dos produtos comercializados. O gráfico a seguir mostra o fluxo de origem dos produtos comercializados no bairro mercadinho.

\section{Gráfico 5: Origem dos produtos comercializados}

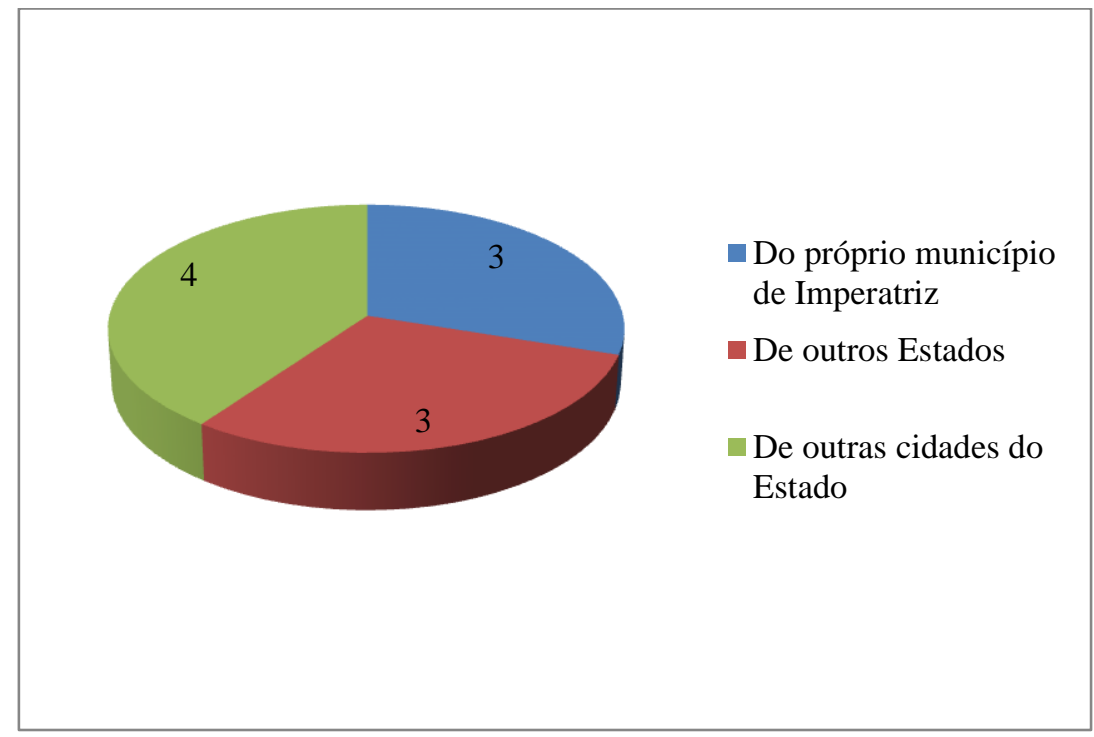

Fonte: Pesquisa direta - Bairro Mercadinho Organização: Bruno Oliveira Lima, 2015.

Os dados obtidos atestam que $40 \%$ dos produtos comercializados no bairro mercadinho são adquiridos de outras cidades do estado do Maranhão. Dos 10 (dez) comerciantes entrevistados, 04 (quatro) afirmaram que adquirem suas mercadorias de diversas cidades do Maranhão, como exemplo Amarante, Grajaú, Balsas e Sítio Novo do Maranhão. Ainda sobre o mesmo questionamento 03 (três) comerciantes, ou seja, 30\% afirmaram que seus produtos são adquiridos no próprio município de Imperatriz e 03 (três) comerciantes 
afirmaram que seus produtos são adquiridos de outros estados, como exemplo, Pará e Tocantins.

No questionamento feito sobre o fluxo de clientes, ou seja, de onde advêm os clientes que compram nos estabelecimentos entrevistados, pudemos perceber o grande poder de atração assumido pelo bairro Mercadinho na cidade de Imperatriz. Todos os comerciantes afirmaram que seus clientes advêm não só desta cidade, mas de cidades vizinhas como João Lisboa, Governador Edison Lobão, Porto Franco, Davinópolis, Senador La Roque, Buritirana entre outras. Ainda informaram que recebem muitos clientes dos estados circunvizinhos, como Pará e Tocantins.

Quando questionados aos comerciantes sobre os motivos que levaram a instalar seus estabelecimentos no bairro Mercadinho, as respostas foram as que seguem no gráfico abaixo, atestando assim, as singularidades que estas formas comerciais do circuito inferior da economia assumem nesta área da cidade.

\section{Gráfico 6: Motivos que levaram os comerciantes a optar em instalar seus empreendimentos comerciais no bairro mercadinho}

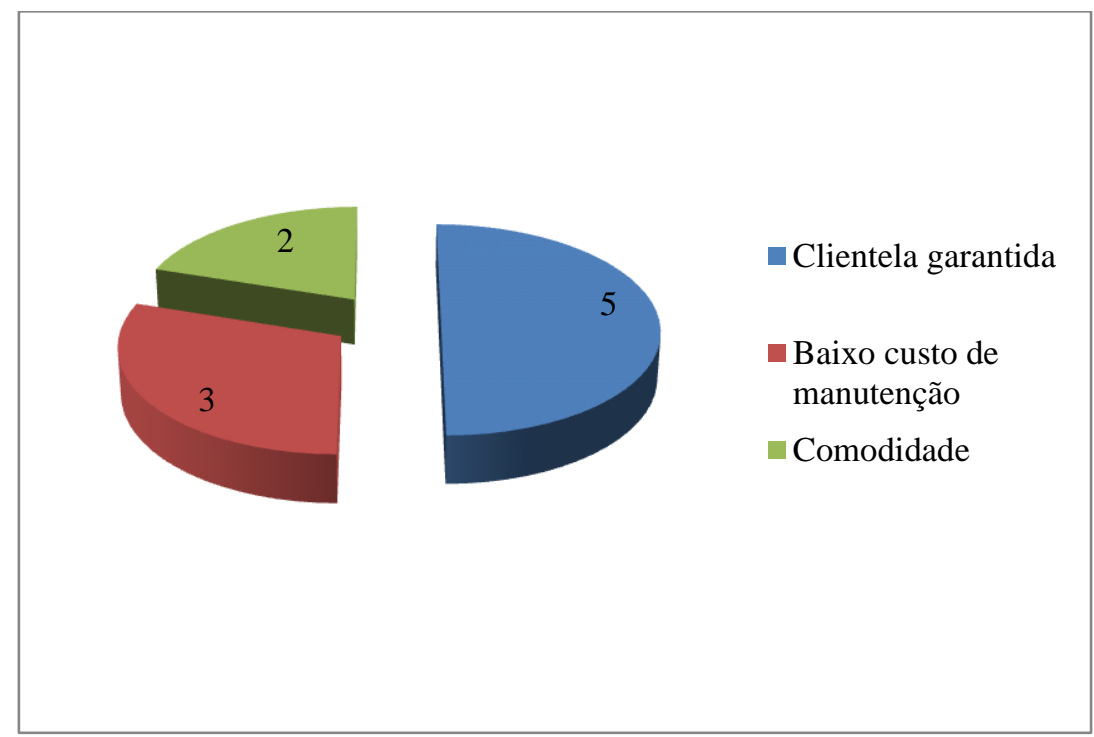

Fonte: Pesquisa direta - Bairro Mercadinho Organização: Bruno Oliveira Lima, 2015.

Pudemos perceber nas afirmativas consideradas pelos comerciantes quando fizeram a escolha do bairro Mercadinho para abrir seus empreendimentos que 50\%, um total de 05 (cinco), optaram em instalar seus empreendimentos por que consideram que a clientela é garantida. Ainda 30\% dos comerciantes entrevistados, num total de 03 (três), optaram pelo bairro Mercadinho por terem baixo custo de manutenção de seus empreendimentos e $20 \%$ dos OBSERVATORIUM: Revista Eletrônica de Geografia, v. 9, n. 3, p. 313-336. set./dez. 2018. 
IMPERATRIZ: uma análise através das dinâmicas materializadas na feira livre do Mercadinho

Bruno Lima; Jailson de Macedo Sousa

comerciantes, num total de 02 (dois), optaram por considerar que têm comodidade para trabalhar no bairro.

Outro questionamento feito aos comerciantes do bairro mercadinho diz respeito se estes consideram o circuito inferior da economia urbana importante para o crescimento da cidade de Imperatriz. Segue abaixo a fala dos entrevistados.

Sim! É eu considero muito importante principalmente porque o mercadinho dá muitas oportunidades para a população, e também porque tem muitas vagas de empregos trazendo assim muitas oportunidades de melhores rendas para as famílias de quem trabalha aqui. (Comerciante 1, entrevistado no bairro mercadinho dia 10/12/2015).

Sim! Porque como no bairro mercadinho abrange em si um número maior de comerciantes em um só lugar, possui também uma visão maior pelos próprios clientes da cidade de Imperatriz e de outras cidades, muita gente só sabe trabalhar aqui, então se isso aqui um dia acabar a cidade vai perder muito. (Comerciante 2, entrevistado no bairro mercadinho dia $10 / 12 / 2015)$.

Sim! Porque nem todas as pessoas podem consumir os produtos do setor formal, e muita gente também não consegue emprego neste setor, então acabam vindo trabalhar aqui, seja como vendedor fixo ou ambulante. Com certeza esse tipo de comércio ajuda no crescimento da economia de Imperatriz, sem o circuito inferior cairia muito todo o comércio desta cidade. (Comerciante 3, entrevistado no bairro mercadinho dia 10/12/2015).

Essas afirmações reforçam ainda mais a ideia de que o circuito inferior da economia possui empreendimentos que garantem um importante e significativo crescimento econômico da cidade de Imperatriz. De modo que se apresentam como importantíssimas formas comerciais na atração de capital e geração de emprego e renda. No último questionamento aberto direcionado aos comerciantes do bairro Mercadinho, foi questionado se o poder público municipal/estadual tem realizado alguma ação no sentido de estruturar este segmento econômico, ou seja, feito algum trabalho para dar mais conforto e comodidade para os comerciantes e clientes. As respostas foram as seguintes.

Não! Em primeiro lugar porque a prefeitura só quer arrecadar a taxa de fixação do estabelecimento aqui no mercado central, o prefeito não quer nem saber se nós temos comodidade ou conforto pra nós ou para nossos clientes. (Comerciante 4, entrevistado no bairro mercadinho dia 10/12/2015).

Sim! Para o próximo ano de 2016 já ouvi dizer que haverá melhorias nos prédios que pertencem à prefeitura, inclusive no mercado central já foi realizada a troca da cobertura das calçadas que estava caindo, isso é sinal de que o prefeito está observando as condições do comércio aqui no bairro mercadinho. (Comerciante 5, entrevistado no bairro mercadinho dia 10/12/2015).

Não! Já faz mais de dez anos que pedimos uma reforma aqui no bairro, mas nada saiu até hoje. As ruas sempre estão muito sujas, esgotos estouram o tempo todo e nós é que limpamos e desentupimos quando isso acontece. (Comerciante 6, entrevistado no bairro mercadinho dia 10/12/2015). 
Nas falas dos comerciantes constatamos que a maioria deles não tem visto nenhuma ação por parte do poder público municipal/estadual no sentido de levar melhorias para o bairro mercadinho, muitos estão insatisfeitos nesse quesito, mas alguns acreditam que, o que é possível está sendo feito. $\mathrm{Na}$ fala de outros comerciantes é elogiada a limpeza das ruas dentro do comércio e afirmam que se há sujeira nestes espaços, são os próprios comerciantes quem as causa.

O conjunto de questionamentos dirigidos tanto aos clientes, como para os comerciantes nos remete a ideia da importância do circuito inferior da economia para a cidade de Imperatriz. Neste quesito, vale lembrar pelo já foi exposto anteriormente, que a cidade de Imperatriz se assume como a mais importante na região Sulmaranhense, de forma que o bairro Mercadinho assume papel de liderança no que diz respeito ao circuito inferior da economia em Imperatriz.

Apesar de o bairro Mercadinho exercer um importante papel de centralidade para a cidade de Imperatriz, como para cidades vizinhas e de outros estados, esta centralidade não tem assegurado preocupações em relação a melhorias ou planejamentos para dar um melhor aspecto para as ruas deste bairro.

\section{Considerações finais}

Tento em vista os problemas, ou seja, as principais indagações que nortearam este estudo, é importante que embasemos nossos esforços no sentido de concluir as reflexões expostas ao longo deste estudo. Para entender a recente dinâmica econômica materializada na cidade de Imperatriz através da forte participação da atividade comercial, em particular, conduzida pelo circuito inferior da economia, foi necessário de início considerar as transformações econômicas presentes na região Amazônica.

A partir da década de 1980, a cidade de Imperatriz pôde experimentar um aumento populacional bastante significativo, sobretudo, em relação à população urbana. Foi também nesta década que esta cidade conheceu condições para a criação de um comércio atacadista, varejista de relevância regional. Pudemos identificar a partir de então, um engajamento e maior participação do setor terciário, que cada vez mais se tornou importante para o crescimento desta cidade. 
O bairro Mercadinho emergiu como uma forma de comércio moderno e não modernizado, acompanhando a tendência brasileira de várias cidades que têm este setor implantado. Neste quesito, estas formas comerciais não modernas têm apresentado papéis essenciais no processo de atração de pessoas, capitais e serviços, reforçando a polarização de Imperatriz no cenário regional Sulmaranhense.

O reconhecimento do bairro Mercadinho da cidade de Imperatriz como formas do circuito inferior da economia, de comercialização de produtos no atacado e varejo, se apresenta como uma análise da realidade urbana desta cidade, por ser uma forma de comércio não organizado, que não visa somente atender os interesses do capital, mas também visa a sobrevivência em primeiro lugar. Apresenta-se como empreendimentos de atração regional bastante significativo no contexto Sulmaranhense.

O que podemos concluir ao fim deste estudo é que a importância assumida pelo bairro Mercadinho extrapola a área urbana de Imperatriz, adotando caráter regional importante à atração de pessoas, bens e serviços. Isto foi percebido ao analisar a clientela dos comércios do bairro mercadinho, oriundos não só desta cidade, mas de toda a região Sulmaranhense e até de outros estados como o Pará e Tocantins.

\section{Notas}

${ }^{1}$ Ciclo do arroz: 1950-1970; Ciclo da madeira: 1960-1980; Ciclo do ouro: 1970-1980.

\section{Referências}

CATAIA, Márcio. SILVA, Silvana Cristina da. Considerações sobre a teoria dos dois circuitos da economia urbana na atualidade. Boletim Campineiro de Geografia, v. 3, n, 1, 2013.

IBGE - Instituto Brasileiro de Geografia e Estatísticas. Cidades do Maranhão. Produto Interno Bruto dos Municípios 2013. Disponível em: 〈http://cidades.ibge.gov.br/〉. Acessado em: 24/07/2016.

LAKATOS, Eva Maria. MARCONI, Maria de Andrade. Fundamentos de metodologia científica. 3 ed. revista e ampliada. São Paulo: Atlas, 1991.

PINTAUDI, Silvana Maria. A cidade e as formas do comércio. In: CARLOS, Ana Fani Alessandri. (Organizadora). Novos Caminhos da Geografia. São Paulo: Contexto, 1999. p. 143-159. 
SANTOS, Milton. O espaço dividido. 2. Ed. São Paulo: Editora da Universidade de São Paulo, 2004.

SOUSA, Jailson de Macedo. A cidade na região e a região na cidade: A dinâmica socioeconômica de Imperatriz e suas implicações na região Tocantina. Dissertação (mestrado em Geografia). Instituto de Estudos Socioambientais da Universidade Federal de Goiás IESA/UFG, 2005.

SOUSA, Jailson de Macedo. Enredos da dinâmica urbano-regional Sulmaranhense: reflexões a partir da centralidade econômica de Açailândia, Balsas e Imperatriz. Tese (doutorado em Geografia). Universidade Federal de Uberlândia/Programa de Pós-graduação em Geografia, 2015. 557p.

SPOSITO, Maria Encarnação Beltrão (organização). Cidades médias: espaços em transição. 1. Ed. São Paulo: Expressão Popular, 2007.

TRINDADE JR, Saint-Clair Cordeiro da. Faces da urbanização na fronteira: a dinâmica metropolitana de Belém no contexto da urbanização Amazônica. Experimental, n.4/5, p.7189, setembro, 1998. 